\title{
A medicalização da educação: implicações para a constituição do sujeito/aprendiz
}

Rita de Cassia Fernandes Signor'

Ana Paula Berberian"

Ana Paula Santanall'

\section{Resumo}

O Transtorno de Déficit de Atenção/Hiperatividade (TDAH) gera controvérsias entre os pesquisadores da área da saúde. A corrente organicista defende que o transtorno seria decorrente de uma desordem neurobiológica, de origem genética. Contrariando o paradigma hegemônico, pesquisadores alinhados à vertente sócio-histórica entendem o TDAH como parte de um fenômeno denominado medicalização da educação. Este estudo pretende refletir sobre a construção social do TDAH (da entrada na escola ao diagnóstico médico) e suas implicações para a subjetividade, socialização e aprendizagem do aluno considerado resistente ao que a escola propõe. Esta pesquisa se constitui em análise de caso, pesquisa de campo, qualitativa, do tipo transversal, inserida em um paradigma teórico-metodológico de cunho sócio-histórico (BAKHTIN, 2006; VYGOTSKY, 2010). Para análise da história de uma criança de 10 anos de idade e com diagnóstico de TDAH, foram realizadas entrevistas com professores, com a mãe e com a criança, observação em sala de aula, avaliação fonoaudiológica e pesquisa documental (material pedagógico, pareceres avaliativos das escolas frequentadas pela criança, pareceres de profissionais de saúde etc.). Os resultados apontam que, quando se investiga em profundidade a qualidade das interações sociais em que a criança esteve/está inserida, é possível que se compreendam as bases socioeducacionais que constituem o suposto transtorno.

\section{Palavras-chave}

I- Universidade Federal de Santa Catarina, Florianópolis, SC, Brasil.

Contato: ritasignor@gmail.com

II- Universidade Tuiuti do Paraná,

Curitiba, PR, Brasil.

Contato: ana.silva17@utp.br

III- Universidade Federal de Santa Catarina, Florianópolis, SC, Brasil.

Contato: anaposantana@hotmail.com
TDAH - Medicalização da infância - Subjetividade Aprendizagem. 


\section{The medicalization of education: implications for the constitution of the subject/learner}

Rita de Cassia Fernandes Signor

Ana Paula Berberian"

Ana Paula Santanall!

\begin{abstract}
Attention deficit hyperactivity disorder (ADHD) generates controversy among researchers in the field of health. Organicists argue that the disorder is the result of a neurobiological, genetic disorder. Countering the hegemonic paradigm, researchers aligned with the social-historical perspective understand ADHD as part of a phenomenon called medicalization of education. This study aims to reflect on the social construction of ADHD (from school admission to medical diagnosis) and its implications for the subjectivity, socialization and learning of students that are seen as resistant to the education proposed by schools. This is a qualitative, cross-sectional field research study (case analysis) conducted within a socio-historical theoretical-methodological framework (BAKHTIN, 2006; VYGOTSKY, 2010). For the analysis of the history of a 10-year-old child diagnosed with $A D H D$, the study used interviews with the child, her teachers and her mother, as well as classroom observation, speech-language evaluation and documentary research (teaching materials, evaluative reports of schools attended by the child, expert opinion from health professionals etc.). Results indicate that in-depth research on the quality of a child's social interactions can shed light on the socio-educational foundations underlying the alleged disorder.
\end{abstract}

\section{Keywords}

ADHD - Medicalization of childhood - Subjectivity - Learning.
I- Universidade Federal de Santa Catarina, Florianópolis, SC, Brasil.

Contact: ritasignor@gmail.com

II- Universidade Tuiuti do Paraná, Curitiba, PR, Brasil.

Contact: ana.silva17@utp.br

III- Universidade Federal de Santa Catarina, Florianópolis, SC, Brasil.

Contact: anaposantana@hotmail.com 


\section{Introdução}

Podemos acompanhar crescente demanda à clínica (médica, fonoaudiológica, psicológica, psicopedagógica) de alunos com dificuldades escolares. Muitos desses sujeitos, após avaliação com especialistas da área da saúde, recebem diagnósticos, dentre os quais destacam-se: Transtorno de Défıcit de Atenção/Hiperatividade (TDAH), Transtorno Desafiante Opositor (TDO), Transtorno bipolar, Transtorno de ansiedade, Transtorno de aprendizagem, Dislexia, dentre outros. Esses transtornos, aprioristicamente, acometeriam funções cerebrais relacionadas à área da linguagem, cognição e/ou aprendizagem.

Queixas a partir das quais ocorrem encaminhamentos de alunos a clínicas de saúde estão, em geral, relacionadas a questões comportamentais, de atenção e de aprendizagem. Prioritariamente formuladas por professores, tais queixas referem-se a alunos que: "não conseguem permanecer sentados por muito tempo"; "pedem para sair da sala constantemente"; "mostram-se distraídos"; "não se engajam nas atividades"; "não copiam do quadro"; "têm escritas em que faltam letras"; "cujos textos não têm sentido"; "têm dificuldades para aprender"; "não conseguem ler"; "são agressivos", "não aceitam regras" etc. Esses relatos acabam sustentando diagnósticos, indicação de tratamentos, e, muitas vezes, prescrição de medicamentos para o controle dos sinais que se manifestam em sala de aula (SIGNOR, 2013).

Diante desses fatos, o número de pessoas que tem recebido o diagnóstico de TDAH, por exemplo, vem crescendo de forma acentuada, o que pode ser constatado a partir do aumento alarmante no consumo de medicamentos (IDUM, 2012). Tal problemática é relevante e promove a necessidade de amplos investimentos em pesquisas nas áreas de saúde e educação a fim de que se implementem alternativas para a superação da excessiva (e crescente) medicalização de crianças e adolescentes.

Os estudos na área são muito abrangentes e é possível observar duas principais tendências teórico-metodológicas que tentam explicar o TDAH. A primeira tendência agrega pesquisadores que, apoiados na corrente positivista (hegemônica), acreditam no determinismo orgânico do TDAH. Segundo a Associação Brasileira do Déficit de Atenção e Hiperatividade (ABDA) ${ }^{1}$, "o TDAH é um transtorno neurobiológico, de causas genéticas, que aparece na infância e frequentemente acompanha o indivíduo por toda sua vida. Ele se caracteriza por sintomas de desatenção, inquietude e impulsividade".

Em direção contrária à anterior, fundamentando uma segunda tendência teórico-metodológica, encontram-se pesquisadores que concebem os chamados Transtornos Funcionais Específicos ${ }^{2}$ como decorrentes de um processo de medicalização da educação, isto é, de redução de questões de cunho social, educacional, político, linguístico, pedagógico e afetivo a aspectos de ordem biológica (MOYSÉS; COLLARES, 2011; MASINI, 2013; GERALDI, 2013; UNTOIGLICH, 2013; SIGNOR; SANTANA, 2013; SIGNOR; SANTANA, 2015; CALIMAN, 2013; MEIRA, 2012).

A fim de explicitar como se sustenta o pensamento positivista que domina as pesquisas da área, é preciso resgatar a história da constituição do TDAH, para que se possa compreender o raciocínio clínico que subsidia o diagnóstico.

Em 1917, na América do Norte, o interesse por desordens que comprometeriam o comportamento e a atenção surgiu após uma epidemia de encefalite, na qual as crianças que sobreviveram começaram a apresentar sequelas comportamentais e cognitivas importantes, ou seja, apresentavam sintomas encontrados

1- Disponível em: <www.abda.com.br>. Acesso em: 04 out.2015.

2- Os chamados Transtornos Funcionais Específicos (TFE) são tradicionalmente entendidos como "um conjunto de sinais ou sintomas que provocam uma série de perturbações no aprender do aluno. [...] Essas desordens são intrínsecas ao sujeito e se devem a disfunções neurológicas que comprometem a aquisição e desenvolvimento de habilidades escolares" (MAKISHIMA; ZAMPRONI, s/d). Inseridos nessa classificação, encontram-se a dislexia, a disortografia, a disgrafia, a discalculia, 0 Distúrbio do Processamento Auditivo Central (DPAC), o Transtorno de Déficit de Atenção/Hiperatividade, entre outros transtornos. 0 público-alvo da Educação Especial (deficiência intelectual, deficiência auditiva, visual e múltipla, surdocegueira, altas habilidades, transtorno do espectro autista) não faz parte dessa classificação. 
no quadro clínico do [que se conhece tradicionalmente por] TDAH, como limitações nas capacidades de atenção e memória e comportamento perturbador (BARKLEY, 2006).

0 aparecimento de sequelas pós-encefalite criou uma hipótese de causa e efeito. Os pesquisadores começaram a supor que, se um dano no cérebro poderia ser responsável pelo surgimento de sintomas na área do comportamento e da atenção, então as crianças que desde a tenra idade já manifestassem esses sintomas os teriam desenvolvido em decorrência de alterações congênitas no cérebro. Moysés e Collares (1992, p. 33) entendem que:

Esse tipo de raciocínio (se A causa B, B só pode ser causado por A) estrutura-se na própria medicina como ciência, numa época em que o objeto de estudo eram basicamente doenças infecto-contagiosas, em que A é um agente biológico bem determinado e externo ao homem; hoje, admite-se a limitação desse raciocínio mesmo nesse grupo de doenças.

No entanto, alegam as referidas autoras, em decorrência de uma formação inadequada de muitos profissionais de saúde, a hipótese de causa e efeito ainda prevalece de forma indiscriminada, mesmo quando não há o envolvimento de aspectos de ordem biológica.

Cabe dizer que o Brasil é o segundo maior consumidor mundial de metilfenidato (IDUM, 2012). Mas, mesmo consumindo um remédio que teria por finalidade controlar a atenção e o comportamento, parte expressiva das crianças não aprende, não se comporta, não se atenta; o que leva a crer que o problema não se reduz aos genes defeituosos; as questões envolvidas são extremamente complexas e difíceis de serem entendidas, talvez em razão de o pensamento dominante ser o organicista, uma vez que se pauta em explicações unidirecionais, que são mais fáceis de serem "apreendidas".

Evidenciando a divergência entre as referidas tendências, destacamos que algumas pesquisas (CASTELLANOS et al., 2002; SHAW et al., 2007; SOWELL et al., 2003) revelam diferenças cerebrais entre pessoas com e sem diagnóstico de TDAH, tais como: diminuição do volume cerebral, atraso na maturação cortical, redução de ativação nas regiões do cérebro envolvendo a área pré-frontal direita, o núcleo caudal, o globus pallidus, o cerebelo e a subregião cerebelar do vermis. Contudo, outras pesquisas (LEO; COHEN, 2003; BAUMEISTER; HAWKINS, 2001; VAILLANCOURT, 2012; LEO; COHEN, 2009) apontam os problemas metodológicos desses estudos.

Leo e Cohen (2003) analisaram mais de trinta estudos de imagem que tiveram por objetivo compreender a relação entre as áreas cerebrais possivelmente afetadas e o TDAH. Os autores afirmam que esses trabalhos não conseguem apresentar uma base biológica sólida para o TDAH, pois apresentam problemas de método. Baumeister e Hawkins (2001) também questionam a confiabilidade dessas pesquisas ${ }^{3}$, considerando os complicadores metodológicos que comprometem o levantamento e a análise dos resultados obtidos.

Dentre esses complicadores, Leo e Cohen (2003) destacam que, na maior parte desses estudos, não são fornecidas informações suficientes a respeito de uma variável importante, que é o uso prévio e/ou continuado de medicação estimulante. Os autores alertam que estudos clínicos e experimentais com animais e humanos têm demonstrado que o uso de drogas psicotrópicas produz efeitos transitórios ou persistentes para o funcionamento e estrutura do sistema nervoso central. Os autores ressaltam, ainda, que alterações podem ser menos ou mais significativas, dependendo de fatores como dose, duração do uso dos medicamentos e estado geral do organismo. Assim, as diferenças encontradas nos cérebros dos grupos com e sem diagnóstico de TDAH (grupo controle)

3- Cabe lembrar que boa parte dessas pesquisas são financiadas pelos laboratórios que produzem os medicamentos. Isso significa que são cerceadas por conflitos de interesses. 
podem estar relacionadas ao uso de medicação estimulante e não a uma alteração constitutiva.

Um estudo organicista bastante mencionado na literatura é o de Castellanos et al. (2002). Essa pesquisa foi realizada durante dez anos, entre 1991 e 2001, com uma amostra de 291 participantes divididos em: 49 pacientes não medicados, 103 pacientes medicados e 139 sujeitos controle. Os pesquisadores realizaram várias comparações: medicados versus não medicados; não medicados versus controle; medicados versus controle.

A mais importante comparação, no entender de Leo e Cohen (2003), foi a categoria dos diagnosticados não medicados e sujeitos controle. No entanto, a comparação não é consistente, pois os não medicados eram dois anos mais jovens do que os do grupo controle. Assim, o resultado de que o volume do cérebro dos pacientes com TDAH é menor do que o das pessoas sem TDAH não se sustenta por meio dessa pesquisa. Para Leo e Cohen (2003), essa variável é muito relevante, pois as pesquisas de tamanho do cérebro têm encontrado correlação com o peso corporal. Alegam os autores que, se os resultados dos estudos anteriores estão contaminados pela variável uso de medicação, o de Castellanos et al. (2002) também está, uma vez que o grupo controle não é comparável ao grupo pesquisado. Além disso, Leo e Cohen (2003, p. 25, tradução nossa) relatam que a única informação a respeito da variável medicação presente no estudo é: "na época da primeira avaliação, 103 pacientes eram tratados com psicoestimulantes". Ou seja, foram desprezados aspectos relevantes tais como: dose, tempo e frequência de uso e tipos de drogas utilizadas.

Um outro aspecto levantado por Leo e Cohen (2003), no que se refere aos estudos de imagem, são as classificações variação biológica normal e doença. Todas as medidas de peso, altura, tamanho do cérebro, nível de atividade, entre outras, caem em uma curva. A linha que delimita o normal e o patológico é arbitrária. E, considerando as imensas variabilidades nas taxas de prevalência desse transtorno e de estudos que mencionam porcentagens exorbitantes, é de se acreditar que o TDAH representa um traço particular, ou seja, pode ser um exemplo de uma variação biológica normal.

Sobre a questão da média estatística para se definir o corte entre o normal e o patológico, Canguilhem (2010) diz que, se o corpo humano é de algum modo produto do meio social, é possível dizer que a constância de certos traços, demonstrados por uma média, dependa da fidelidade (in)consciente a algumas normas da vida. Assim, "na espécie humana, a frequência estatística não traduz apenas uma normatividade vital, mas uma normatividade social. Um traço humano não seria normal por ser frequente, mas seria frequente por ser normal, isto é, normativo num determinado gênero de vida" (CANGUILHEM, 2010, p. 115-116).

As pesquisas de prevalência do TDAH têm indicado taxas altas de crianças que receberam esse diagnóstico. Por exemplo, um estudo realizado por Fontana et al. (2007), em quatro escolas públicas brasileiras, em uma população de 602 escolares, com 461 participantes, os pesquisadores chegaram a um percentual de 13\% de crianças que, após avaliação médica, receberam o diagnóstico. Percebe-se, assim, com base nos pressupostos de Canguilhem, que o TDAH não é normal por ser frequente, mas é frequente por ser normal.

Entendemos, ainda, que a dificuldade em encontrar um marcador biológico para o TDAH se apoia nas posições de Signor (2013) de que a criança não é desatenta e/ou hiperativa em todas as situações. Há uma imensa heterogeneidade manifesta em comportamentos e atitudes que se diferenciam a depender de uma série de fatores, sobretudo os interacionais e contextuais. Dito de outro modo, se uma criança é, por exemplo, superatenta a jogos eletrônicos ${ }^{4}$, como supor a possibilidade de que uma imagem do cérebro possa demonstrar que ela não se atenta apenas às atividades escolares? Acreditamos, desse modo, que não é uma questão de desatenção,

4- Atividade que, aliás, exige mecanismos atencionais apuradíssimos. 
mas de deslocamento do foco atentivo. Se houvesse uma homogeneidade nas atitudes, ou seja, se a criança fosse regularmente desatenta ou regularmente hiperativa, poderíamos supor que esse comportamento atípico poderia imprimir seus efeitos no cérebro ou até mesmo ser consequência de uma alteração cerebral.

Nessa direção, destacamos também estudos que concebem o cérebro como um órgão plástico, flexível e dinâmico e defendem a ideia de que possíveis diferenças cerebrais podem estar relacionadas a esse aspecto. Rubia (2002) afirma que pessoas submetidas a eventos emocionais significativos podem apresentar redução do hipocampo e ativação anormal da amígdala, o que corrobora a noção de que a experiência social faz parte do desenvolvimento da estrutura e funcionamento cerebral, conforme Vygotsky (2004).

Consoante a esse posicionamento, Leo e Cohen (2004) consideram que as diferenças cerebrais (ou "anormalidades") podem ser consequência, em vez de uma característica da síndrome ou do comportamento, e essa questão não poderia ser relativizada pelos pesquisadores.

Outros estudos nessa direção foram resgatados por Cortese e Castellanos (2012). Com base no critério de busca TDAH e imagem (na base Pubmed), os pesquisadores organicistas analisaram os artigos publicados entre janeiro de 2011 e abril de 2012 e chegaram à conclusão de que a literatura atual continua contribuindo para a emergência de modelos que visam a explicar mecanismos fisiopatológicos subjacentes ao TDAH. No entanto, os autores admitem que é prematura qualquer reinvindicação desse instrumento como ferramenta para diagnóstico ou plano de tratamento, devendo ser usado tão somente para fins de pesquisa.

Vê-se, assim, que hipóteses continuam a sustentar os achados obtidos por meio das pesquisas da área. Logo, tais pesquisas ainda são muito incipientes para oferecer uma explicação sobre a possível base neuro(bio)lógica do TDAH. Para além das razões anteriormente mencionadas, entendemos também que o caráter orgânico do TDAH não pode ser comprovado, pois o diagnóstico desse suposto transtorno, como explicam Moysés e Collares (2011), é baseado em critérios vagos, subjetivos e inconsistentes, como pode ser observado na lista de características do TDAH presentes no Manual diagnóstico e estatístico de transtornos mentais. Dentre essas características estão: "perde as coisas", “é distraído", "sai do lugar na sala de aula”, "se remexe na carteira", "frequentemente está a todo vapor", "tem dificuldade de esperar a vez", "fala em excesso", "interrompe os outros, se intromete", "corre e escala em demasia”, "não termina seus deveres escolares", entre outros "sintomas" que, entendemos, decorrem de aprendizagens sociais e podem se modificar a depender do contexto em que a criança está. Assim, a título de exemplificação, um aluno pode se remexer na carteira na aula do professor X e permanecer atento e interessado à aula do professor Y.

Em suma, pesquisas pautadas no paradigma dominante correlacionam os sintomas a uma suposta doença neuropsiquiátrica. A contracorrente, por sua vez, está representada por um grupo de pesquisadores que baseia suas discussões sobre o TDAH no conceito de medicalização, entendendo que possíveis sintomas podem ser decorrentes de relações de sofrimento que foram sendo construídas mediante a inserção do sujeito nas práticas sociais. Entende-se, ainda, que existem diferentes características e perfis de personalidade e as ações infantis não podem ser correlacionadas a priori a manifestações sintomáticas.

Segundo Meira (2012), a medicalização da educação tem servido para justificar o fracasso escolar de crianças que, embora permaneçam na escola por longos períodos de tempo, não se apropriam dos conteúdos veiculados. Desse modo, atribuir as dificuldades escolares às características orgânicas/cerebrais do estudante oculta os condicionantes sociais, culturais, políticos, educacionais, afetivos e ideológicos envolvidos na produção do chamado TDAH.

Um resgate histórico da educação no Brasil nos oferece elementos para compreender como um modelo reducionista (biologizante) vem sendo 
produzido e disseminado em e por diferentes contextos e grupos sociais, fundamentando análises e explicações para o fracasso escolar e os baixos níveis de alfabetismo que atingem parcela significativa da população brasileira (BERBERIAN, 2007). Estudos (PATTO, 2010; MOYSÉS, 2001) indicam que o início do século XX marca um forte acolhimento pelas práticas educacionais pautadas nos ideários biomédicos e psicométricos. As autoras evidenciam como explicações de cunho organicista para as dificuldades do aprender e do se comportar na escola estão comprometidas com posições teórico-práticas que situam nos alunos e/ ou em seus familiares a causa de tais problemas.

Abordagens clínicas e educacionais, ao transformarem processos de caráter social em problemas de ordem biológica - patologização da aprendizagem -, geram implicações que não apenas incidem na trajetória escolar dos alunos, mas acabam se estendendo para outras esferas da vida dos sujeitos. Podemos acompanhar crianças que, estigmatizadas como más leitoras, más escritoras, hiperativas, desatentas, entre outras classificações, tornam-se desmotivadas em relação à escola. No caso da linguagem escrita, a internalização da dificuldade, muitas vezes já pré-anunciada precocemente no contexto da escola (por educadores que desconsideram o caráter heterogêneo dos processos de aprendizagem), costuma gerar uma rejeição importante a ler e produzir textos, conduzindo às chamadas dificuldades de leitura e escrita. Isso ocorre porque, distantes de práticas de leitura e escrita, os alunos têm poucas possibilidades de desenvolver competências linguístico-discursivas necessárias ao enfrentamento de demandas em uma sociedade grafocêntrica.

Entendemos que cabe aos profissionais que lidam com a criança analisar a que aspectos as queixas e os sintomas apresentados podem estar relacionados:

- A problemas emocionais significativos que podem levar à desatenção, uma vez que cognição e emoção são aspectos indissociáveis?
- A práticas de letramento pouco desafiadoras e descontextualizadas que podem gerar sinais de distanciamento e alheamento dos alunos?

- A processos de estigmatização (rótulos) que podem gerar resistências ao que é proposto pela escola?

- Às características individuais da criança?

0 objetivo deste artigo é analisar as bases socioeducacionais que constituem o chamado TDAH e suas implicações para a subjetividade, socialização e apropriação da linguagem escrita por parte do aluno considerado hiperativo/desatento ${ }^{5}$ ("resistente" ao que é proposto pela escola).

\section{Metodologia}

A fim de analisar de que forma o chamado TDAH se constrói no contexto das práticas escolarizadas (discursos, ações e práticas de letramento) e suas implicações, analisamos aqui a trajetória histórica de uma aluna com esse diagnóstico. Para tanto, desenvolveu-se um estudo de caso, pesquisa de campo, qualitativa, do tipo transversal, inserida em um paradigma teórico-metodológico de cunho sócio-histórico (VYGOTSKY, 2010; BAKHTIN, 2006). Foi selecionada uma aluna, denominada como Susi, de 10 anos de idade, estudante (à época da coleta de dados, 2012) do quinto ano do ensino fundamental da rede pública de Santa Catarina (Brasil).

Partimos da hipótese de que os processos de significação - a discursivização desfavorável do aluno $^{6}$ e as práticas de letramento descontextualizadas - podem afetar a subjetividade e a aprendizagem da criança, levando à constituição do sintoma.

5- Aluno considerado hiperativo/desatento é aquele que é patologizado (rotulado) na escola, mas que ainda não recebeu o diagnóstico médico. Analisa-se aqui o papel da queixa escolar na constituição do diagnóstico de TDAH e suas implicações para o aluno.

6- 0 que se fala dele; 0 que se fala para ele. A discursivização desfavorável representa o conjunto de discursos que desqualificam a criança. 
Os procedimentos da pesquisa envolveram: entrevistas com a mãe da criança e com a criança, avaliação fonoaudiológica individual, observação da aluna em sala de aula por um período de uma semana, entrevistas com professores e orientadora educacional e pesquisa documental (pareceres avaliativos da escola, agendas, cadernos, pastas com atividades - atuais e pregressos). Os dados foram registrados por meio de gravação em áudio e diário de campo.

Este estudo pretende promover reflexões para profissionais da educação e da saúde sobre as implicações de processos medicalizantes vivenciados por parte expressiva de escolares. Pautada em uma concepção constitutiva de linguagem, que preconiza que os sujeitos se constituem em suas relações sociais mediadas pela linguagem (BAKHTIN, 2006), a pesquisa está orientada para a análise da qualidade das interações sociais nas quais o sujeito com diagnóstico de TDAH está/esteve inserido, e, por conseguinte, para a possível necessidade de ressignificá-las.

A pesquisa $^{7}$ foi aprovada pelo Comitê de Ética em Pesquisa da Universidade Federal de Santa Catarina, sob o processo 94.405. Foram assinados os Termos de Consentimento Livre e Esclarecido por todos os participantes da pesquisa.

A seguir, a apresentação da criança.

\section{Apresentando Susi}

Susi vive com sua mãe (pedagoga aposentada, 52 anos) em um condomínio de classe média de um município em Santa Catarina. Seu pai reside no Rio Grande do Sul. Na ocasião da pesquisa, a separação do casal havia ocorrido há dois anos, ou seja, quando Susi tinha 8 anos de idade.

Dos 2 aos 5 anos, Susi frequentou, em período integral, uma escola de educação infantil pública. No primeiro e segundo anos do

7- Este estudo foi financiado com recursos do Conselho Nacional de Desenvolvimento Científico e Tecnológico (CNPq). ensino fundamental, a menina estudou, também em período integral, em uma escola privada. Do terceiro ano ao momento da pesquisa (quinto ano), estudou em uma escola da rede pública de ensino no período da manhã.

Susi realizou avaliação psicológica aos 5 anos de idade, pois havia queixas constantes da escola sobre o seu comportamento. Segundo a mãe, tais queixas referiam-se ao fato de que: "Susi não queria fazer as atividades, não obedecia, imitava a professora, brigava com os amigos...". Aos 6 anos de idade, a criança foi encaminhada para avaliação psiquiátrica, recebeu o diagnóstico de TDAH, indicação de tratamento medicamentoso, psicopedagógico e orientação de continuidade do atendimento psicológico, que realizava desde os 5 anos.

Quanto ao processo de ensino-aprendizagem da leitura e escrita, segundo a mãe de Susi, a filha teve dificuldades na alfabetização e conseguiu aprender a ler e escrever apenas no terceiro ano, por uma questão de "sorte". A mãe relatou que a sorte ocorreu porque naquele ano Susi teve uma "professora maravilhosa".

\section{A escola e a constituição da subjetividade da criança}

Para explicitação das representações sobre a criança na época da educação infantil, apresentamos um recorte de um "parecer avaliativo" de quando Susi tinha 2 anos e 4 meses de idade:

É extremamente inteligente, compreende tudo o que acontece ao seu redor, assimilando as propostas e regras do grupo, o que não significa que ela as cumpra. Susi mostra-se bastante resistente quando é contrariada, falamos ou pedimos algo a ela. [...] É considerada a tagarela da turma, pois fala pelos cotovelos; repete tudo o que falamos e as vezes fico surpresa, parecendo um adulto chamando atenção dos outros, dando ordens e cobrando atitudes dos colegas. Susi nos mostra o quanto é esperta, 
o tempo todo tentando jogar conosco; quando precisamos chamar sua atenção, mostra-se bastante resistente e reage de forma que "não tô nem aí". Conversamos e explicamos várias vezes e nada; quando precisamos afastá-la um pouco do grupo para pensar o que fez, ela respondendo fala que não fará mais. Isto nos mostra que ela está bem consciente de seus atos e que realmente sabe o que está fazendo. Espero que nós adultos casa/escola, que convivemos com Susi, possamos fazer um trabalho coerente para que ela não entre em conflito e choque de posturas. Nos demais aspectos do desenvolvimento como motor, cognitivo e linguagem, ela apresenta um crescimento dentro do esperado para a sua idade. (Parecer avaliativo da escola, 2004, grifos nossos).

Conforme trecho acima, podemos notar que, aos 2 anos de idade, a criança já estava sendo discursivizada de forma depreciativa e discriminatória. Para análise dos efeitos desses enunciados para a constituição da subjetividade de Susi, recorremos às formulações de Bakhtin (2009). 0 autor afirma que a motivação do comportamento de um sujeito, isto é, "a consciência de si mesmo" é a colocação de si mesmo sob determinada norma social, é a socialização de si mesmo e do seu ato: "Ao tomar consciência de mim mesmo, eu tento como que olhar para mim pelos olhos de outra pessoa, de outro representante do meu grupo social" (2009, p. 86-87).

Ainda, pelo excerto, percebe-se que, por ser considerada "esperta" (no sentido pejorativo do termo), "resistente" e "autoritária”, a criança era convocada a pensar: "quando precisamos afastá-la um pouco do grupo para pensar o que fez". Tal procedimento, segundo a mãe, era constantemente adotado pelas educadoras. Encaminhada ao "cantinho do pensamento" para refletir sobre seus atos considerados inadequados, Susi permanecia assimilando que crianças que não atendem a um padrão esperado devem ser afastadas de seu grupo de convivência.
Ao tentar higienizar as diferenças, muitas escolas ensinam que ter comportamentos distantes de uma média é um traço negativo. Os alunos considerados problema e seus colegas vivenciam a exclusão. E, nesse processo de internalização de uma dada condição, todos assimilam que os resistentes são desviantes e que, por isso, não podem ser acolhidos. Desse ponto de vista, a exclusão social não é um sintoma do chamado TDAH, como apregoam os pesquisadores organicistas, mas decorre, sobremaneira, de questões delegadas às ações estabelecidas em algumas escolas.

Para Vygotsky (2010, p. 311), se na criança foram criadas formas antissociais de comportamento, a regra para a reversão do problema é justamente o contrário daquela aplicada aos infratores das leis na sociedade, onde a medida é a exclusão do meio social: "Ali, é ínfima a preocupação com a personalidade do próprio infrator, e tudo se volta para neutralizá-lo e proteger o meio de sua influência”. Na escola, assegura o autor, a regra é distinta; isto é, a regra é o contato social mais estreito, pois é na convivência mediada que as crianças desenvolvem capacidades ligadas à criação e manutenção de laços afetivos.

Vale destacar que, na atualidade, aos 10 anos de idade, Susi apresenta sérios problemas relacionais com os colegas e sofre os efeitos dessa situação. Paralelamente a esse fato, ela se diz "agitada" e com "dificuldades de aprendizagem”. Para analisarmos como tais posições acerca de si foram sendo constituídas por Susi, cabe adentrarmos às interações vivenciadas por ela e significações e fatos que culminaram no diagnóstico de TDAH.

\section{A constituição do diagnóstico de TDAH e os processos de aprendizagem da criança}

A partir dos 5 anos de idade, as queixas dos educadores acerca de Susi se estenderam do campo comportamental e relacional para a esfera da aprendizagem, conforme pode ser apreendido no trecho abaixo apresentado: 
Em seus desenhos representa elementos soltos pelo espaço do papel, faz bonecos e sol, com poucos detalhes. Não compõe muitas cenas. [...] Conversa bastante e desconcentra-se rapidamente durante atividades individuas de escrita e desenho. Susi aprecia atividades de dança, música e representação corporal. (Parecer avaliativo da escola, 2007, grifos nossos).

Quanto às observações de que a criança se desconcentrava em atividades de escrita e desenho, vale realizarmos algumas considerações. Inicialmente lembramos que, desde que tinha 2 anos de idade, Susi estava submetida a um círculo de interações negativas na escola. Isto é, há três anos, ouvia que seu comportamento era inadequado e era advertida sobre isso e afastada da convivência de seu grupo. Assim, formulamos a hipótese de que, a essa altura, esses discursos vivenciados pela criança afetaram sobremaneira a sua subjetividade. Considerando a relação entre linguagem e subjetividade (BAKHTIN, 2006), é possível supor que ela começou a manifestar desinteresse pela escola e pelas atividades realizadas naquele local.

Atrelada às questões subjetivas, Susi foi submetida a práticas de letramento distantes de um contexto vivencial e significativo, conforme aponta o discurso da mãe (pedagoga). Essa constatação pôde ser realizada ainda por meio de análise do material pedagógico (cadernos, pastas com atividades e exercícios). Muitas das atividades desenvolvidas na educação infantil estavam restritas a exercícios de escrever à sua maneira palavras ao lado de figuras dadas e, ainda, à escrita de palavras e frases ditadas pela professora. Dentre as atividades realizadas por Susi, aos 5 anos e 5 meses de idade, optamos por apresentar duas delas, datadas em 2007:

Entendemos que, inseridos em práticas de letramento descontextualizadas, os alunos tendem a responder de forma chamada desinteressada e desatenta, podendo resistir ou sujeitarem-se às mesmas, fato que gera implicações para os processos de aprendizagem. De acordo com
Vygotsky (2010, p. 163), “toda a aprendizagem só é possível na medida em que se baseia no próprio interesse da criança. Outra aprendizagem não existe". Ainda nos termos do autor:

Figura 1 - Atividade da educação infantil

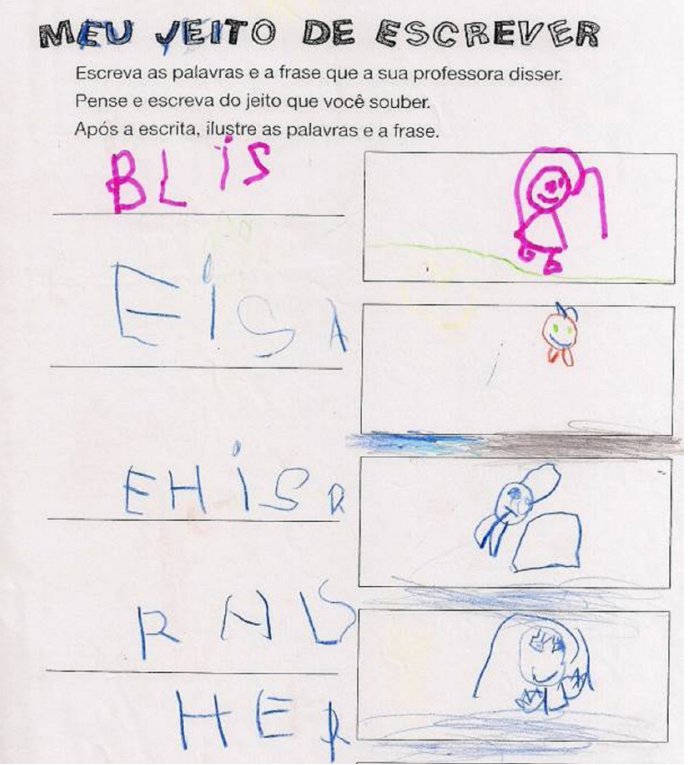

Fonte: material da pesquisa.

Figura 2 - Atividade da educação infantil

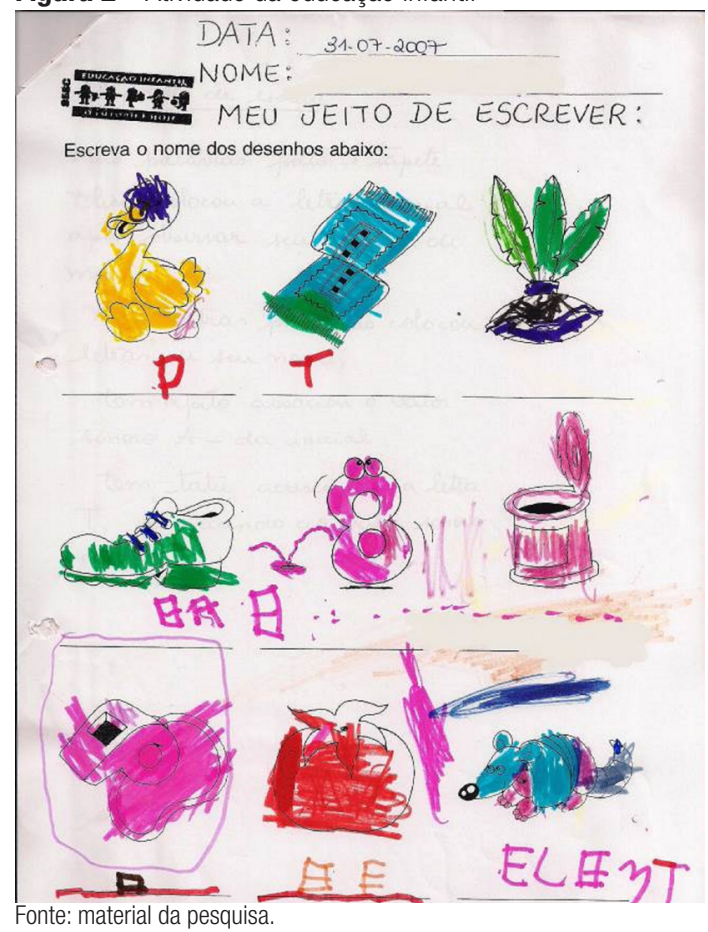


A atenção infantil é orientada e dirigida quase exclusivamente pelo interesse, e por isso a causa natural da distração da criança é sempre a falta de coincidência de duas linhas na questão pedagógica: do interesse propriamente dito e daquelas ocupações que são propostas como obrigatórias.

[...].

É por isso que o velho sistema escolar, que tomava a divergência entre essas duas linhas como base de sabedoria psicológica, era forçado a apelar para medidas externas de organização da atenção, a avaliar a atenção dos alunos com uma nota especial e, em essência, sofria de total impotência para elaborar as devidas formas de atitude (VYGOTSKY, 2010, p. 162).

Apoiados nas ponderações de Vygotsky (2010), acreditamos que atividades pautadas em ditados de palavras e frases não despertam o real envolvimento dos alunos. Susi foi submetida a interações sociais desfavoráveis e práticas de letramento ineficazes - e se opôs a elas. Ocorre que essa resistência foi compreendida pela escola como um sinal de que algo não ia bem. E a família foi cada vez mais levada a acreditar nisso.

Aos 5 anos e 7 meses, outro parecer da escola dizia:

Reconhece poucas letras do alfabeto, apesar das frequentes atividades e brincadeiras relacionadas ao letramento. Em atividades de escrita espontânea faz uso apenas do repertório de letras de seu nome, fazendo poucas relações com o som das letras nas palavras. (Parecer avaliativo da escola, 2007, grifos nossos).

De acordo com o excerto, "reconhecer poucas letras do alfabeto" e "utilizar apenas o repertório de letras de seu nome" - aos 5 anos de idade - representa um problema. Acreditamos que esse tipo avaliação pode trazer efeitos nocivos para a criança. Para Berberian, Mori de Angelis e Massi (2006, p. 21):

Projeções negativas em torno do percurso que grupos de crianças estariam predestinados a trilhar e previsões de que deficiências e alterações fazem parte desse percurso reduzem processos de aquisição da leitura e escrita à constituição e/ou à confırmação de problemas precocemente anunciados. Tal armadilha é, sem dúvida, um dos principais problemas vividos pelas crianças ao longo desse processo, bem como por aqueles que participam de sua vida. A expectativa negativa reduz as possibilidades de domínio da leitura e escrita.

Segundo as autoras, para o diagnóstico na área da linguagem escrita, é preciso que se leve em conta várias questões: práticas de letramento familiar, práticas de letramento escolar, significado da leitura e da escrita para a criança, acesso à cultura escrita, relações afetivas, dentre outras. Ou seja, não se nega que as crianças possam ter dificuldades; o que se nega é que essas dificuldades sejam precocemente consideradas como distúrbios individuais, sem que se considere as práticas sociais e discursivas que medeiam o processo de apropriação da escrita. Ademais, no caso de Susi, não há um problema detectável. Aos 5 anos de idade, usar prioritariamente as letras do nome faz parte do processo de aquisição da escrita. Não pode ser tomado como indicativo de uma alteração na área da aprendizagem.

Após a educação infantil, Susi foi matriculada em uma escola particular, onde realizou o primeiro e o segundo anos do ensino fundamental, em período integral. Quando indagada acerca do processo de aprendizagem da leitura e escrita, a mãe respondeu que “ela se alfabetizou com quase 8 anos... Mas é que a gente não deu sorte na escola que ela frequentou o primeiro ano... Ela foi para uma escola que era extremamente conteudista e não atendia essas particularidades...”. E continuou: 
0 psiquiatra foi na escola, a psicóloga foi na escola, mas eles não tinham um trabalho... aliás nenhuma escola tá preparada pra esse tipo de criança... que tá cada vez mais presente nas escolas... não fazem nenhum trabalho diferenciado... aí ela não conseguiu se alfabetizar... no $2^{\circ}$. pro $3^{\circ}$. ano a escola queria reprovar... daí eu contestei, fui até a secretaria de educação, eles acabaram aprovando ela...

(Entrevista com a mãe, maio de 2012).

A escolha pela nova escola se deu pela localização (próxima à residência da família) e também por ser mais acessível economicamente. Nessa escola, segundo a mãe, as queixas continuaram: "ali continuou a questão do relacionamento... que não gostavam dela... que ela brigava muito... [...] isso tudo a Susi já com atendimento...”.

Quando pedimos à mãe que nos especificasse o termo "conteudista" mencionado por ela para se referir à prática pedagógica assumida pela escola, obtivemos a seguinte explicação:

Mãe: Eu ia também bastante conversar com a professora... no final do período... falava da questão dos conteúdos... que achava que era muito conteúdo... [..]

Pesquisadora: Tinha algum método de alfabetização?

Mãe: Era o silábico... a escola se dizia Freinet, mas de Freinet não tinha nada... eu não via pelo menos... era ba be bi bo bu... pegava todas as consoantes... ia trabalhando consoante por consoante... [...] bem tradicional... e então no $2^{\circ}$. ano a Susi ainda não escrevia o nome dela... não conseguia escrever... tinha dificuldade. (Entrevista com a mãe).

A fim de analisar as práticas de letramento desenvolvidas na escola, tivemos acesso aos cadernos de Susi do primeiro e segundo anos e uma pasta com as atividades realizadas durante esses anos. Observemos, abaixo, uma atividade desenvolvida em 2008, com vistas à apropriação da leitura e escrita, quando a aluna frequentava o primeiro ano do ensino fundamental.

Figura 3 - Atividade do primeiro ano

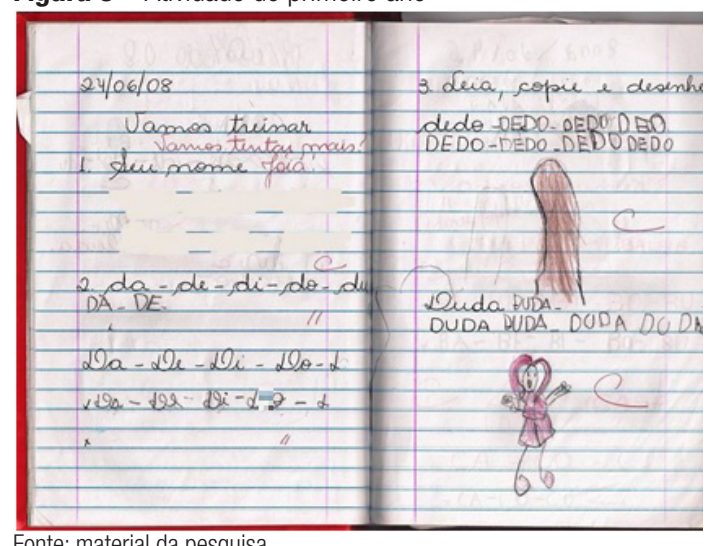

Fonte: material da pesquisa.

Analisando no material de Susi as atividades desenvolvidas, foi possível apreender a concepção de letramento que pautava as práticas de escrita na escola. Houve ali uma independência entre alfabetização e letramento, como se os dois processos não fossem inter-relacionados. Para Soares (2004), dissociar alfabetização e letramento é um equívoco porque, no quadro das atuais concepções psicológicas, linguísticas e psicolinguísticas de leitura e escrita, a entrada da criança (e também do adulto analfabeto) no mundo da escrita ocorre simultaneamente por esses dois processos: pela aquisição do sistema convencional de escrita - a alfabetização - e pelo desenvolvimento de habilidades de uso desse sistema em atividades de leitura e escrita, nas práticas sociais que envolvem a língua escrita - o letramento.

Acrescente-se ainda que a concepção de letramento que se tem trabalhado em muitas escolas é a de letramento autônomo. Para Street (2014), no modelo autônomo de letramento, a escrita é apartada dos seus contextos de uso.

Analisar tais questões nos faz entender por que a menina estava tão distante dessas práticas; em uma das atividades, havia a menção 
de que a aluna estava dormindo no momento da atividade. E, no segundo ano, conforme afirma a mãe, a filha ainda não escrevia o próprio nome de forma independente.

Em um dos exercícios observados no caderno, como consta da figura 3, percebemos que Susi era levada a "treinar" a escrita de seu nome, repetindo-o diversas vezes. Nessa direção, levantamos a seguinte pergunta: De que forma, nesses contextos nada significativos, a criança pode se apropriar da leitura e da escrita? Entendemos que a escrita do nome deve ser incentivada como uma forma de marcar a autoria: o nome que assina um desenho produzido pela criança, ou uma pintura, uma produção de texto. São nesses contextos, em que a escrita do nome é necessária, que ela deve ser requerida, não de maneira repetida e aleatória, em forma de treino, desprovida de função.

Evidenciando atividades escolares pautadas na noção de que a apropriação da escrita ocorre a partir de repetições e memorizações, pudemos observar nos cadernos de Susi, ainda, exercícios cuja finalidade era cobrir letras pontilhadas, segmentos consonantais e vocálicos e de famílias silábicas, confirmando relatos da mãe. Pudemos verificar, nos cadernos analisados, o predomínio dessas atividades, evidenciando o quanto a escola estava impermeável aos pressupostos veiculados pelos Parâmetros Curriculares Nacionais de Língua Portuguesa (BRASIL, 1998).

Com base nas diretrizes nacionais, a apropriação da linguagem escrita se dá num espaço de dialogia. Assentadas nas formulações de Bakhtin (2006, p. 111), orientações contidas em tais documentos concebem que a língua não pode ser transmitida, porque ela "dura e perdura" sob um contínuo processo de evolução: "Os indivíduos não recebem a língua pronta para ser usada; eles penetram na corrente da comunicação verbal; ou melhor, somente quando mergulham nessa corrente é que sua consciência desperta e começa a operar". Desse modo, somente no fluxo do discurso é que o sujeito pode percorrer um caminho de apropriação consciente da língua escrita em todas as suas dimensões, pois, ao operar com e sobre a linguagem, ao refletir com e sobre a linguagem, estará ampliando seus conhecimentos acerca da leitura e da escrita.

Dando seguimento ao percurso escolar de Susi, apresentamos uma atividade desenvolvida em 2009, época em que Susi frequentava o segundo ano do fundamental e tinha 7 anos de idade:

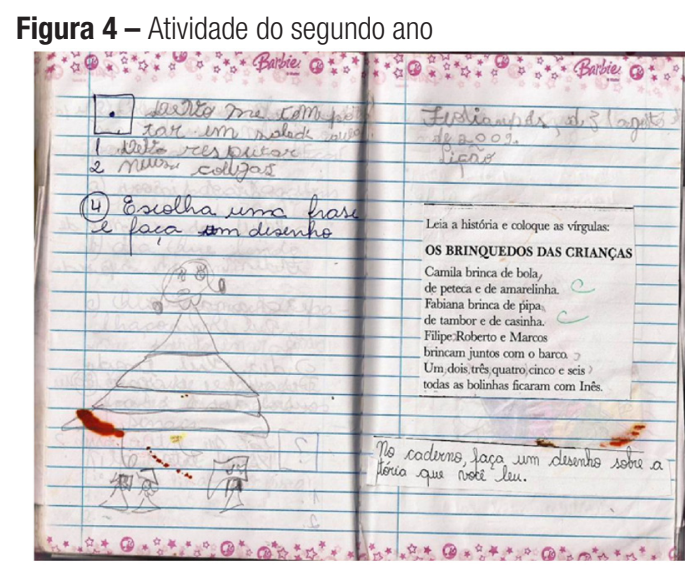

Fonte: material da pesquisa.

Note-se que, no canto superior esquerdo, está escrito: "Devo me comportar em sala de aula. Devo respeitar meus colegas”. Como não estava alfabetizada nesse período, hipotetizamos que Susi teve de copiar frases que veiculavam a noção já enraizada por ela de que "não respeitava", "não se comportava". Pensamos que a repetição dessas frases teve por objetivo favorecer a permanência da aluna em um lugar de desaprovação.

$\mathrm{Na}$ página seguinte, ainda na figura 4, observamos: "Leia a história e coloque as vírgulas"; "No caderno faça um desenho sobre a história que você leu". Consideramos que a apresentação do pseudotexto "Os brinquedos das crianças”, além de não contribuir para a entendimento e aprendizagem da pontuação requerida (a vírgula), pode limitar as potencialidades de reflexão e análise linguística por parte das crianças, bem como conduzir à noção de que ler e escrever são atividades mecânicas e desprovidas de sentido. 
Desse modo, observando a artificialidade com que Susi foi introduzida ao mundo da leitura e escrita na escola, é possível perceber sua recusa em engajar-se nas propostas requeridas e também a sua "dificuldade" em se alfabetizar. Consideramos que as concepções de linguagem e aprendizagem subjacentes ao fazer pedagógico refletem um processo de alfabetização pautado em um método que pressupõe atividades de treino, cópia e repetição de segmentos isolados, sílabas e palavras. Desfaz-se assim, no caso de Susi, o jogo intersubjetivo inerente à aprendizagem da língua em sua modalidade escrita. E, com isso, modifica-se o olhar do aluno sobre o objeto do conhecimento. Os alunos passam a acreditar que escrever é codificar e ler é decodificar. Ademais, ficam emaranhados em um círculo de interações negativas, à mercê de um discurso autoritário, e sujeitos a atividades que não têm outro fim senão aniquilar quaisquer interesses pela leitura e escrita. $\mathrm{E}$, dessa forma, entram em ação os profissionais da saúde para tratar, como pode ser visto nos pareceres avaliativos abaixo, dos "problemas" apresentados no decorrer da escolaridade:

Apresentou neste [primeiro] bimestre
muita desatenção. Porém aos poucos
vem concluindo seus trabalhos. Você é
capaz fofa! (Parecer avaliativo da escola -
segundo ano, grifos nossos).

Neste [segundo] bimestre, Susi demonstrou muitas dificuldades na compreensão dos conteúdos apresentados necessitando de uma maior atenção e concentração para concluir seus trabalhos.

Estou sempre com você. (Parecer avaliativo da escola - segundo ano, grifos nossos).

Após análise das atividades escolares de Susi, é possível compreender a "muita desatenção" e as "muitas dificuldades na compreensão dos conteúdos" como efeitos de um processo de ensino e aprendizagem. 0 docente, muitas vezes, não consegue chamar a atenção das crianças e torna a compreensão dos conteúdos quase inacessível ao aluno, uma vez que não domina questões básicas para que sua prática seja efetiva. Além disso, como já discutido, a questão não estava apenas relacionada às práticas. A esse tempo, Susi já deveria ter internalizado parte dos discursos acerca de si e de suas "capacidades", o que pode ser reiterado ao analisarmos dialogicamente $o$ enunciado: "Você é capaz fofa!".

E, no parecer avaliativo final, apresentado à família ao término do segundo ano, é perceptível o desejo de que a aluna fosse reprovada. A aprovação se deu em virtude de questões alheias à professora. Inclusive, há a previsão de que a aluna "terá grandes desafios a superar":

Susi apresentou um desempenho regular. Permanece a necessidade da continuidade com a psicopedagoga e orientação constante dos pais quanto aos estudos. Respeitando o processo de inclusão frequentará o $3^{\circ}$. ano e terá grandes desafios a superar. Feliz Natal! (Parecer avaliativo da escola segundo ano, grifos nossos).

Vale ressaltar que a trajetória escolar de Susi foi norteada por previsões negativas acerca de seu futuro escolarizado. "A escola queria reprovar”, disse a mãe, e só não o fez porque a mãe recorreu à secretaria de educação para buscar os direitos da filha. Para analisarmos os efeitos gerados por reprovações de alunos, recorremos às formulações de Foucault (2009). 0 autor afirma que a escola se configura em um "aparelho de exame ininterrupto" que acompanha o cumprimento das operações de ensino, em um espaço de comparação de um com todos, que possibilita medir e sancionar. E o exame não tem por finalidade apenas medir o aprendizado; ele representa a afirmação do poder seletivo da escola. Esse "poder disciplinar” é invisível, diz o autor, mas impõe uma visibilidade aos que são submetidos ao mesmo.

Ressalte-se que, no caso de Susi, as previsões da escola sobre os desafios a serem enfrentados não foram concretizadas, o que pode ser evidenciado na discussão a seguir. 


\section{A afetividade na relação professor- -aluno e o desenvolvimento da criança na escola}

Findo o segundo ano, Susi foi transferida para uma escola pública municipal e passou a frequentá-la apenas no período matutino:

Mãe: Quando ela veio para o (colégio X) ela teve uma sorte, ela pegou uma professora maravilhosa...

Pesquisadora: Foi com quantos anos isso? Mãe: Com 8 anos, no 3o. ano... [...] Aí foi onde ela deslanchou... a Jaque tinha uma prática assim mais ou menos diferenciada... E foi aí que ela deslanchou com a leitura e a escrita dela... que até então ela tinha bastante dificuldade... (Entrevista com a mãe, maio de 2012).

Durante conversa com Susi, pudemos observar que a professora do terceiro ano tinha uma postura diferenciada, acolhedora, e sua afeição por ela se faz presente no discurso da menina, que se refere à professora como uma pessoa "doce":

Susi: A única professora que eu fui com a cara dela, que eu gosto dela realmente, é a Jaque...

Pesquisadora: E como é que é a Jaque? Me conta.

Susi: A Jaque é doce... Ela ensina as pessoas bem... [...] Às vezes eu falo: "Jaque, não tem uma vaga pra mim de novo?" (Entrevista com a criança).

Considerações de Susi acerca da professora também puderam ser apreendidas por meio de bilhetes no caderno: "Professora, você é demais. É tudo de bom que existe nesse mundo. Com amor, Susi." Pelas respostas da professora, pode-se acompanhar o estabelecimento de uma interação construtiva entre ambas: "Muito obrigada, você é uma aluna muito querida, te adoro, beijinhos...." Segundo a mãe, Susi constantemente escrevia bilhetes para essa professora e foi um ano muito tranquilo porque não havia queixas e reclamações sobre a filha; ao contrário, havia elogios: "Qualquer coisa ela elogiava, valorizava muito a produção deles”.

Evidenciando a importância do estabelecimento de interações a partir das quais a criança é posta no lugar de sujeito capaz, pudemos entender os avanços na aprendizagem relatados pela mãe. Se, conforme Vygotsky (2004), a cognição se constitui na interação, é por meio do olhar do outro (o professor) que a criança se torna "atenta" ou "desatenta", "ativa" ou "hiperativa”, "boa” ou "má" aprendiz. Assim, o sintoma pode (ou não) ser produzido a depender do contexto interacional.

Há de se entender, nessa direção, a relevância da afetividade para o desenvolvimento da criança na escola. A professora do terceiro ano conquistou a aluna. Muito da boa relação professor-aluno passa por esse processo de conquista. 0 professor que valoriza o aluno cria uma espécie de comprometimento com ele. Ao se comprometer com o aluno e com a sua aprendizagem, o professor recebe o comprometimento do aluno também. 0 aluno não há de querer decepcionar alguém que espera algo dele ou que espera muito dele; se é valorizado, tenderá a querer corresponder às expectativas de quem o valoriza. Esse processo faz parte da natureza das relações humanas e coaduna com a concepção de sujeito responsivo (BAKHTIN, 2006). 0 sujeito responde às interações nas quais está inserido; responde de forma favorável às interações que propiciam o desenvolvimento e a aprendizagem e de forma opositiva às interações desfavoráveis.

0 caderno do terceiro ano demonstra que Susi teve um grande progresso no desenvolvimento da escrita. Apresentamos, na página 16, duas produções de texto, realizadas em 2009 (segundo ano) e 2010 (terceiro ano).

Ao contrapormos as referidas atividades, bem como a menção de que no terceiro ano Susi “deslanchou", é possível afirmarmos que o desenvolvimento da aprendizagem aconteceu por questões afetivo-volitivas e não foi 
Figura 5 - Atividade do segundo ano

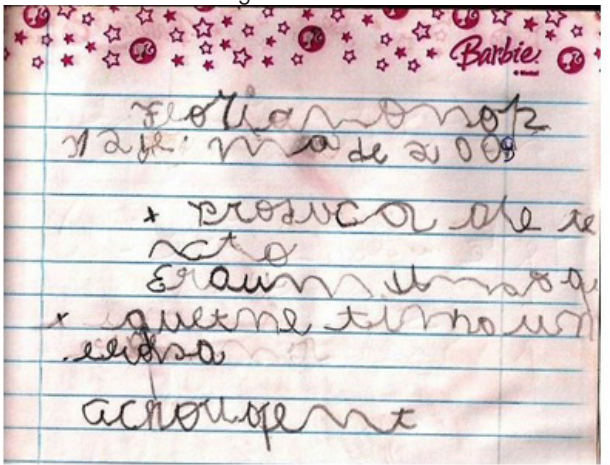

Fonte: material da pesquisa.

decorrente, portanto, de um diagnóstico e de um medicamento. No entanto, para a família, professores e mesmo para a criança, há a aderência ao discurso que aponta a melhora decorrente do uso de medicação. Tal aderência fortalece o fenômeno da medicalização de escolares. A seguir, apresentamos indícios de como esse processo se constrói.

\section{Eles precisam de remédio?}

Ao ser indagada em relação à sua visão sobre o diagnóstico de Susi, a mãe mencionou que inicialmente manifestava resistência (não aceitação) - como o pai da menina -, mas, ao observar melhora na capacidade de se concentrar por parte da filha, acabou por aceitar a conduta adotada pelo médico: "Eu a princípio também era contra, mas depois, quando ela começou a usar [o medicamento], e eu vi que ela começou a se concentrar mais e se apropriar dos conteúdos da escola... eu percebi uma diferença...".

Algo comum é a resistência inicial ao diagnóstico, mas, depois de inserida no processo de patologização, a família acaba por ser convencida de que o filho tem problemas, conforme Moysés (2001). Esse processo de convencimento pode ser explicado por meio do conceito de discurso competente (CHAUI, 2014). Chaui entende que aquele que possui um saber determinado (0 médico? 0 professor?), institucionalmente reconhecido, adquire o
Figura 6 - Atividade do terceiro ano

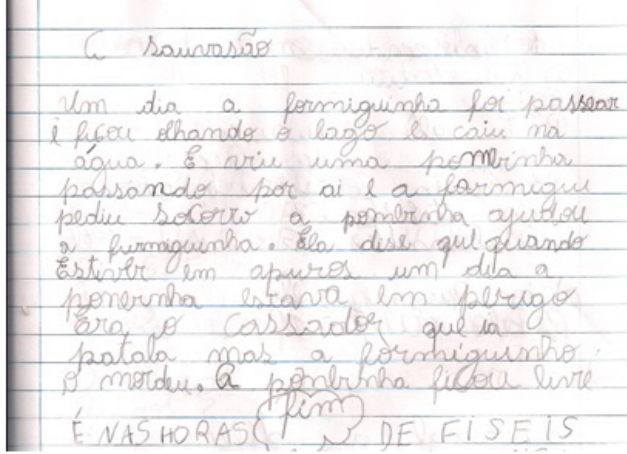

direito de falar e agir pelo outro, destituindo-o da sua condição de sujeito. 0 discurso competente é, na realidade, um exercício de dominação onde se opera uma divisão: os competentes (os que detêm o saber científico e, portanto, exercem o poder) e os incompetentes sociais (os dominados). Esse conceito encontra ressonância na noção de medicalização de Ivan Illich. Em seu livro A expropriação da saúde: nêmesis da medicina, de 1970, o autor apontava que a amplificação do poder médico minimizava as possibilidades de os sujeitos lidarem com suas perdas da vida cotidiana, uma vez que transformava sofrimento em doença. E, assim, crianças normais estão se tornando crianças doentes, até que, "doentes" transformam-se em consumidoras de medicamentos (MOYSÉS; COLLARES, 2013).

Embora a mãe relate melhora decorrente da medicação, seu discurso revela uma contradição:

Pesquisadora: Com 6 anos ela já tomava Ritalina e mesmo assim ela teve dificuldades pra se alfabetizar?

Mãe: Mas eu acho que a dificuldade maior foi por conta da escola...

Pesquisadora: Por conta da escola... Tá, mas você fala que ajudou na concentração... eu quero entender como esse medicamento surte algum efeito positivo na sua opinião... Mãe: Porque daí ela não fica muito dispersa... Pesquisadora: E você acha que ela é dispersa? Mãe: Ela é dispersa. 
[...].

Mãe: Eu acho que ela é dispersa... Porque eu também sou um pouco assim... também acho que eu tenho um pouco de déficit de atenção...

Pesquisadora: Você acha que tem?

Mãe: Acho que tenho. Então... a gente pede pra ela fazer uma coisa... "daqui a pouco”... daqui a pouco ela nem sabe mais o que a gente pediu... o que ela tinha que fazer mesmo... essas coisas, né, mas isso também é normal... escovar dente... tomar banho... se eu não mando, não sai... [...] e... perde muito as coisas... perde muito os objetos... hoje ela já deixou o casaco... (Entrevista com a mãe).

É possível verificar que, mesmo tomando uma medicação desde os 6 anos de idade, a criança, como já dito, só foi alfabetizada dois anos depois. A mãe tem consciência de que o problema foi pedagógico ("a dificuldade maior foi por conta da escola"), mas a maioria dos familiares não tem a mesma noção. Contudo, a mãe, tentando justificar o inexplicável, apresenta argumentos que só fazem confirmar as hipóteses de que não há um problema orgânico.

Dizer "daqui a pouco" a um pedido da mãe e depois esquecer o que fora pedido, só escovar os dentes e tomar banho a mando, deixar o casaco e perder os objetos podem ser tomados como sinais de um transtorno neurobiológico (uma dispersão patológica)? Ou tais características fazem parte da realidade das crianças de uma forma geral? Pensamos que crianças de 10 anos que tomam banho e escovam os dentes de forma espontânea o fazem porque foram disciplinadas para isso. Muito comum ainda são os pais, como a mãe de Susi, culparem-se pelos problemas apresentados: "eu também tenho um pouco de déficit de atenção". Há de se perguntar: quem não tem um pouco de déficit de atenção? Talvez por ouvirem do médico que o transtorno é de base genética e que, portanto, pode ter sido herdado, já fiquem a procurar quais os seus defeitos que foram transmitidos ao filho.

Entendemos que, se a ideologia opera de certo modo como uma representação da realidade e se essa representação é socialmente formada, podemos atuar como analistas de discurso num embate ideológico. Se os sujeitos assumem uma visão de uma realidade que lhes é dada e se essa realidade os faz acreditar que portam supostas patologias no campo da aprendizagem e comportamento, podemos tentar reverter determinadas crenças construindo outras crenças. Entre as ações que nos são possíveis, em situação de clínica fonoaudiológica ${ }^{8}$, está a promoção do letramento. 0 fato de o sujeito/ paciente começar a se ver como alguém capaz porque vivencia em terapia contextos significativos de uso da linguagem, e com isso desenvolve competências linguístico-discursivas, já representa a apreensão de valores que colaboram na desconstrução da concepção hegemônica da realidade pregressa. Conduz-se, desse modo, à geração de outros valores que, carregados de novos sentidos, fazem crer que é possível que se estabeleça uma mudança de postura frente à linguagem e à condição de sujeito/aprendiz.

\section{Considerações finais}

Freitas (2007), ao olhar a educação sob uma ótica bakhtiniana, realiza algumas perguntas que vão ao encontro das nossas inquietações no que diz respeito às relações estabelecidas entre alunos e professores em algumas escolas. Nessa direção, a autora pergunta: a sala de aula é um lugar de uma só voz ou um local onde diferentes discursos se intercruzam? 0 professor fala a um aluno abstrato ou a um sujeito situado histórica e socialmente? E defende que: "Educar não é homogeneizar, produzir em massa, mas produzir singularidades. Deixar vir à tona a diversidade

8- Os adeptos da corrente sócio-histórica não negam a existência dos problemas. 0 que se nega é que 0 TDAH seja uma condição biológica do sujeito. Desse modo, acolhemos algumas das crianças que nos são encaminhadas para que possamos ressignificar relações sofriveis decorrentes de processos patologizantes. 
de modos de ser, de fazer, de construir: permitir a réplica, a contrapalavra" (FREITAS, 2007, p.147, grifos nossos).

Bakhtin (2003, p. 348) entende que, no enfoque monológico, o outro permanece apenas objeto da consciência e não outra consciência: "O monologismo nega ao extremo, fora de si, a existência de outra consciência isônoma e isônoma-responsiva, de outro eu (tu) isônomo". Assim, no meio educacional, pautado no monologismo, a educação é correlacionada à sujeição do aluno e não decorre, portanto, da negociação das diferentes ideias que se instauram em qualquer situação de grupo. 0 problema é que a domesticação para a obediência pode causar desequilíbrios/resistências nas crianças. Muitas delas reagem às formas impositivas de dominação. Os resultados podem ser observados nas próprias de salas de aula, que muitas vezes mais parecem campos de batalha entre alunos e professores do que espaço de pluralidade de vozes e socialização de conhecimentos.

0 problema se agrava quando a criança é encaminhada para os serviços de saúde para que receba um parecer médico e um tratamento para seus "distúrbios" de comportamento e de aprendizagem. Assim, após confirmado na clínica o pré-diagnóstico escolar, a criança passa a ser prisioneira de uma condição que não é sua. Submetida a essa condição, as ações da criança passam a ser analisadas em meio às siglas que lhe são atribuídas: "a criança esquece o casaco porque tem TDAH”; “a criança tem dificuldades na escola porque tem déficit de atenção"; "a criança não obedece porque é TOD”; "a criança não consegue escrever porque é disléxica” etc. Ao ser discursivizada pelo outro por meio de enunciados desqualificatórios, o aluno passa a viver em estado de sofrimento e a desenvolver sintomas, os quais tendem a reiterar o diagnóstico (SIGNOR, 2013).

No caso aqui analisado, vimos que a criança apresentou dificuldades no processo de alfabetização sem ter qualquer alteração orgânica que, por ventura, justificasse a dificuldade apresentada. Em detrimento das práticas cristalizadas de ensino da leitura e escrita, pôde-se observar o quanto a visão redutora sobre a menina (e suas capacidades) afetou a sua subjetividade, a sua capacidade de se relacionar e a sua aprendizagem.

Cabe mencionar, entretanto, que, da mesma forma que a discursivização e as expectativas desfavoráveis afetaram negativamente o desenvolvimento da criança, a discursivização favorável conduziu a avanços. Por meio da história de Susi, foi possível observar que interações sociais afetivas repercutem na promoção da aprendizagem. Essas interações, atravessadas por uma visão dialógica do aluno, sugerem a compreensão do caráter multifacetado e inconcluso do sujeito, bem como revelam o entendimento relacionado ao fato de que os indivíduos são inseridos em processos históricos e coletivos. Esse olhar dialógico favorece que o aluno construa uma autoimagem positiva. Tais relações favoráveis são fundamentais para que a criança tenha chances de reagir/resistir ao processo de assujeitamento e, com isso, possa minimizar a relação muitas vezes sofrida estabelecida com a escola e com a própria condição de sujeito relacional e de aprendiz (SIGNOR, 2013).

Acreditamos que há a necessidade de uma profunda reflexão sobre os problemas que se apresentam em relação à escola brasileira. Leite (2007) afirma que tal reflexão possibilitaria uma revisão crítica de nossas representações sobre o homem, a sociedade que queremos construir, o papel do Estado e da escola, o processo de produção de conhecimentos, a relação família-escola, os valores que a escola não pode se eximir de trabalhar com seus alunos, enfim, seria um processo que possibilitaria uma ampla ressignificação de nossos referenciais políticos e ideológicos. Esse processo de reflexão sobre a educação contribuiria para a promoção de um sistema educacional voltado para a formação da consciência crítica e da cidadania transformadora: “Tal inserção não se pode dar de forma isolada, mas em parceria com 
educadores de boa vontade, comprometidos com a escola democrática - destacando-se a figura do professor e do gestor escolar" (LEITE, 2007, p. 304). 0 autor afirma que a escola não pode ser vista como um simples aparelho manipulado pelo Estado em função somente da ideologia das classes dominantes, mas como um lugar de confronto de ideias e valores no qual devem estar presentes profissionais atuando na direção da contracorrente, tornando, assim, a escola um espaço de reflexão importante para a promoção de um ensino de boa qualidade.

Ao final deste texto, esperamos ter demonstrado que o estudo do TDAH em contraposição ao conceito de medicalização é fundamental para evidenciar que temos diferentes formas de interpretação da realidade. Este trabalho mostrou a multiplicidade de facetas que envolve a normalidade e a patologia no que se refere à atenção, comportamento e aprendizagem. Vale ressaltar que não estamos relativizando a existência de problemas reais que possam requerer recursos suplementares à educação formal na escola ou mesmo atendimento com profissionais de saúde; o que estamos discutindo é a construção de um transtorno que tem sido concebido à margem das práticas sociais.

\section{Referências}

AMERICAN PSYCHIATRIC ASSOCIATION. Diagnostic and statistical manual of mental disorders. 5. ed. Arlington: American Psychiatric Association, 2013. (DSM 5).

ASSOCIAÇÃO Brasileira de Déficit de Atenção. Disponível em: <www.abda.com.br>. Acesso em: 4 out. 2015.

BAKHTIN, Mikhail. Estética da criação verbal. São Paulo: Martins Fontes, 2003.

BAKHTIN, Mikhail. Marxismo e filosofia da linguagem. São Paulo: Hucitec, 2006.

BAKHTIN, Mikhail. 0 freudismo. São Paulo: Perspectiva, 2009.

BARKLEY, Russel A. Transtorno de Déficit de Atenção/Hiperatividade: manual para diagnóstico e tratamento. Porto Alegre: Artmed, 2006.

BAUMEISTER, Alan; HAWKINS, Michael F. Incoherence of neuroimaging studies of attention deficit/hyperactivity disorder. Clinical Neuropharmacology, Philadelphia, v. 24, n. 1, p.2-10, Jan./Feb. 2001.

BERBERIAN, Ana Paula. Fonoaudiologia e educação: um encontro histórico. São Paulo: Plexus, 2007.

BERBERIAN, Ana Paula; MORI DE ANGELIS, Cristiane C.; MASSI, Giselle. Letramento: referenciais em educação e saúde. São Paulo: Plexus, 2006.

BRASIL. Parâmetros Curriculares Nacionais (PCNs): língua portuguesa. Ensino fundamental. Terceiro e quarto ciclos. Brasília, DF: MEC/SEF, 1998.

CALIMAN, Luciana Vieira. Os bio-diagnósticos na era das cidadanias biológicas. In: COLLARES, Cecília Lima; MOYSÉS, Maria Aparecida Affonso; RIBEIRO, Mônica França (Org.). Novas capturas, antigos diagnósticos na era dos transtornos. São Paulo: Mercado de Letras, 2013. p. 119-133.

CANGUILHEM, Georges. 0 normal e o patológico. Rio de Janeiro: Forense Universitária, 2010.

CASTELLANOS, Francisco Xavier et al. Developmental trajectories of brain volume abnormalities in children and adolescents with attention deficit/hyperactivity disorder. JAMA, v. 28, p. 1740-1748, 2002.

CHAUI, Marilena. A ideologia da competência. São Paulo: Autêntica, 2014. Organizado por André Rocha. 
CORTESE, Samuele; CASTELLANOS, Francisco Xavier. Neuroimaging of attention-deficit/hyperactivity disorder: current neuroscience-informed perspectives for clinicians. Current Psychiatry Reports. v. 14, n. 5, Oct. 2012.

FONTANA, Rosiane et al. Prevalência de TDAH em quatro escolas públicas brasileiras. Arquivos de Neuro-Psiquiatria, São Paulo. v. 65, n. 1, 2007.

FOUCAULT, Michel. Vigiar e punir. Petrópolis: Vozes, 2009.

FREITAS, Maria Teresa de A. A perspectiva sócio-histórica: uma visão humana da construção do conhecimento. In: FREITAS, Maria Teresa de A.; SOUZA, Solange Jobim; KRAMER, Sonia. Ciências humanas e pesquisa: leituras de Mikhail Bakhtin. São Paulo: Cortez, 2007. p. 26-37.

GERALDI, João Wanderley. Educação sem enxada e sem ritalina: alfabeto, alfabetização e higienização. In: COLLARES, Cecília Lima; MOYSÉS, Maria Aparecida Affonso; RIBEIRO, Mônica França (Org.). Novas capturas, antigos diagnósticos na era dos transtornos. São Paulo: Mercado de Letras, 2013. p. 311-322.

IDUM. Instituto de Defesa dos Usuários de Medicamento. Brasília, DF: IDUM, 2012. Disponível em: <www.idum.org.br>. Acesso em: mar. 2015.

LEITE, Sergio Antonio da Silva. A construção da escola pública democrática: algumas reflexões sobre a política educacional. In: SOUZA, Beatriz de Paula. Orientação à queixa escolar. São Paulo: Casa do Psicólogo, 2007. p. 281-306.

LEO, Jonathan L.; COHEN, David. Broken brains or flawed studies? A critical review of ADHD neuroimaging studies. The Journal of Mind and Behavior, Orono, v. 24, n. 1, p. 29-56, Win. 2003.

LEO, Jonathan L.; COHEN, David. The truth behind brain scans. The Journal of Mind and Behavior, Orono, v. 25, n. 2, p. 161166, Spr. 2004

MAKISHIMA, Édne Aparecida Claser; ZAMPRNI, Eliete Cristina Berli. Transtornos funcionais específicos. In: SÃO PAULO (Estado). Secretaria de Estado da Educação. Departamento de Educação Especial e Inclusão Educacional. São Paulo: SEE, [20--].

MASINI, Lucia. Uma nova criança exige uma nova escola. In: COLLARES, Cecília Azevedo Lima; MOYSÉS, Maria Aparecida Affonso; RIBEIRO, Mônica França (Org.). Novas capturas, antigos diagnósticos na era dos transtornos. São Paulo: Mercado de Letras, 2013. p. 181-190.

MEIRA, Marisa Eugênia Melillo. Para uma crítica da medicalização na educação. Psicologia Escolar Educacional, Maringá, v. 16, n. 1, p.136-42, jan./jun. 2012.

MOYSÉS, Maria Aparecida Affonso. A institucionalização invisível: crianças que não-aprendem-na-escola. São Paulo: Mercado de Letras, 2001.

MOYSÉS, Maria Aparecida Affonso; COLLARES, Cecília Azevedo Lima. A história não contada dos distúrbios de aprendizagem. Cadernos CEDES, :Campinas, n. 28, p. 31-47, 1992.

MOYSÉS, Maria Aparecida Affonso; COLLARES, Cecília Azevedo Lima. Dislexia e TDAH: uma análise a partir da ciência médica. In: CONSELHO REGIONAL DE PSICOLOGIA DE SÃO PAULO (Org.). Medicalização de crianças e adolescentes: conflitos silenciados pela redução de questões sociais a doença de indivíduos. São Paulo: Casa do Psicólogo, 2011.

PATTO, Maria Helena Souza. A produção do fracasso escolar: histórias de submissão e rebeldia. São Paulo: Casa do Psicólogo: 2010.

RUBIA, Katya. The dynamic approach to neurodevelopmental psychiatric disorders: use of FMRI combined with neuropsychology to elucidate the dynamics of psychiatric disorders, exemplified in ADHD and schizophrenia. Behavioral Brain Research, v. 130, n. 1-2, p. 47-56, Mar. 2002.

SHAW, P. et al. Attention-deficit/hyperactivity disorder is characterized by a delay in cortical maturation. PNAS, Bethesda, v. 104, n. 49, p. 19649-19654, Dec. 2007. 
SIGNOR, Rita. 0 sentido do diagnóstico de transtorno de déficit de atenção e hiperatividade para a constituição do sujeito/ aprendiz. 2013. Tese. (Doutorado em Linguística) - Universidade Federal de Santa Catarina, Florianópolis, 2013.

SIGNOR, Rita.; SANTANA, Ana Paula. A outra face do TDAH. Distúrbios da Comunicação, São Paulo, v. 27, n. 1, p. 39-54, 2015.

SIGNOR, Rita; SANTANA, Ana Paula. Transtorno de déficit de atenção/hiperatividade: implicações para a linguagem escrita. In: MOURA, Heronides; MOTA, Mailce; SANTANA, Ana Paula (Org.). Cognição, léxico e gramática. Florianópolis: Insular, 2013. p. 175-200.

SOARES, Magda Becker. Letramento e alfabetização: as muitas facetas. Revista Brasileira de Educação, Rio de Janeiro, v. 25, p. 5-17, jan./abr. 2004.

SOWELL, Elizabeth R. et al. Cortical abnormalities in children and adolescents with attention-deficit hyperactivity disorder. The Lancet, v. 362, n. 9397, p. 1699-1707, nov. 2003.

STREET, Brian V. Letramentos sociais: abordagens críticas do letramento no desenvolvimento, na etnografia e na educação. São Paulo: Parábola, 2014.

UNTOIGLICH, Gisela. Usos biopolíticos do suposto transtorno de déficit de atenção e hiperatividade: que lugar para o sofrimento psíquico na infância? In: COLLARES, Cecília Azevedo Lima; MOYSÉS, Maria Aparecida Affonso; RIBEIRO, Mônica França (Org.). Novas capturas, antigos diagnósticos na era dos transtornos. São Paulo: Mercado de Letras, 2013. p. 119-132.

VAILLANCOURT, Jean-Philippe. L'origine neurologique du trouble déficitaire de l'attention avec ou sans hiperactivité: fait ou hypothèse? Revue Québécoise de Psychologie, Quebec, v. 33, n. 1, p. 253-270, 2012.

VYGOTSKY, Lev Semenovitch. Psicologia pedagógica. São Paulo: Martins Fontes, 2010.

VYGOTSKY, Lev Semenovitch. Teoria e método em psicologia. São Paulo: Martins Fontes, 2004.

Recebido em: 04.03.2015

Aprovado em: 17.12.2015

Rita de Cassia Fernandes Signor atualmente é fonoaudióloga do Hospital Infantil Joana de Gusmão e integrante do Grupo de Estudos em Linguagem, Cognição e Educação (GELCE) da Universidade Federal de Santa Catarina (UFSC), com apoio do Conselho Nacional de Desenvolvimento Científico e Tecnológico (CNPq).

Ana Paula Berberian atualmente é professora adjunta da Universidade Tuiuti do Paraná, atuando nos cursos de graduação em fonoaudiologia e no Programa de Doutorado e Mestrado em Distúrbios da Comunicação. Participa da linha de pesquisa Fonoaudiologia e os Processos de Linguagem.

Ana Paula Santana é professora adjunta do curso de fonoaudiologia da Universidade Federal de Santa Catarina e da pósgraduação em linguística na mesma universidade. 
